\title{
ASUHAN KEBIDANAN PADA IBU YANG MEMILIKI BAYI USIA 7 - 8 BULAN TENTANG PEMBERIAN MP-ASI DI PMB ERNITA PEKANBARU TAHUN 2020
}

\author{
${ }^{1)}$ Nur Israyati , ${ }^{2}$ Aprilia Willa Puspita \\ STIKES HANG TUAH Pekanbaru
}

\begin{abstract}
INTISARI
Makanan Pendamping ASI (MP-ASI) merupakan makanan atau minuman tambahan yang mengandung zat gizi dan diberikan mulai usia $6-24$ bulan untuk memenuhi kebutuhan gizi selain dari ASI. Setelah bayi berusia 6 bulan, kebutuhan zat gizi makin bertambah seiring dengan pertumbuhan dan perkembangan bayi, sementara produksi ASI mulai menurun, karena itu bayi membutuhkan makanan tambahan sebagai pendamping ASI. Pemberian makanan tambahan yang tidak tepat kualitas dan kuantitasnya dapat menyebabkan gizi kurang yang berdampak pada gangguan pertumbuhan dan perkembangan apabila tidak segera diatasi. Penelitian ini bertujuan untuk mengetahui pengetahuan ibu yang memiliki bayi usia 7- 8 bulan tentang pemberian MP-ASI sesuai usia bayi. Metode studi kasus ini menggunakan metode deskriftif observasional dengan pendekatan continuity of care diberikan pada ibu yang memiliki bayi usia $7-8$ bulan Ny.R di PMB Ernita, Amd.Keb dari 27 agustus - 02 september 2020. Subjeknya Ny. R umur 27 tahun P1A0. Jenis data primer. Cara pengumpulan data anamnesis, observasi, pemeriksaan dan dokumentasi. Analisa data dengan membandingkan antara data yang diperoleh dengan teori yang ada. Laporan kasus dan bahasan : Ny.R mengatakan belum mengerti cara membuat menu MP-ASI sesuai usia bayinya, pada pemberian MP-ASI pertama bayinya sempat mengalami susah buang air besar (BAB). Simpulan : Asuhan kebidanan dilaksanakan menggunakan pendekatan dengan pendokumentasian SOAP ( Subjektif, Objektif, Asesmen, Penatalaksanaan) ditemukan kesenjangan pada data subjektif dan objektif. Sehingga setelah semua data terkumpul dapat disimpulkan Analisa dan melakukan penatalaksanaan sesuai dengan teori.

Diharapkan kepada penyedia layanan asuhan kebidanan yang membuka praktik dapat memberikan penyuluhan dan praktek mengolah menu pada ibu yang mempunyai bayi usia 6-24 bulan tentang pemberian MP-ASI yang tepat dan sehat sesuai dengan usia bayinya. Agar dapat meningkatkan pengetahuan ibu dan bisa mengolah menunya sendiri sesuai dengan usia bayinya.
\end{abstract}

Kata kunci : Asuhan Kebidanan, MP-ASI, bayi usia 7-8 bulan 


\section{PENDAHULUAN}

Makanan Pendamping ASI (MPASI) merupakan makanan atau minuman tambahan yang mengandung zat gizi dan diberikan mulai usia 6 -24 bulan untuk memenuhi kebutuhan gizi selain dari ASI. Setelah bayi berusia 6 bulan, kebutuhan zat gizi makin bertambah seiring dengan pertumbuhan dan perkembangan bayi, sementara produksi ASI mulai menurun, karena itu bayi membutuhkan makanan tambahan sebagai pendamping ASI. Pemberian makanan tambahan yang tidak tepat kualitas dan kuantitasnya dapat menyebabkan gizi kurang yang berdampak pada gangguan pertumbuhan dan perkembangan apabila tidak segera diatasi (Mutalib 2014).

Faktor penting untuk memaksimalkan periode emas pertumbuhan otak adalah terpenuhinya nutrisi. Pemberian makanan yang tepat serta optimal sangatlah penting untuk kelangsungan hidup, tumbang (pertumbuhan \& perkembangan) bayi dan anak sejak usia 0 hingga 2 tahun.Menurut Global Strategy on Infant \& Young Child Feeding, pemberian makanan yang tepat adalah menyusui bayi sesegera mungkin setelah lahir (IMD/InisiasiMenyusu Dini), memberikan ASI eksklusif sampai usia 6 bulan, dilanjutkan pemberian MPASI (Makanan Pendamping ASI) yang tepat \& mencukupi sejak usia 6 bulan, dan melanjutkan pemberian ASI sampai usia 2 tahun/lebih. Makanan yang paling baik untuk bayi segera lahir adalah ASI.ASI mempunyai keunggulan baik ditinjau segi gizi, daya kekebalan tubuh, psikologi, ekonomi dan sebagainya.Setelah bayi berusia 6 bulan, maka sudah waktunya memperkenalkan makanan pendamping ASI pada bayi.Bayi membutuhkan zat-zat gizi tinggi untuk pertumbuhan dan perkembangannya. Seiring bertambahnya usia bayi, kebutuhan zat gizinya juga meningkat. Makanan pendamping ASI (MP-ASI) merupakan makanan tambahan bagi bayi.Makanan ini harus menjadi pelengkap dan dapat memenuhi kebutuhan bayi (Sitompul 2014)

Beberapa penelitian yang dilakukan oleh Hermina dan Nurfi (2010), menyatakan bahwa masalah gizi pada bayi dan anak disebabkan kebiasaan pemberian ASI dan MP-ASI yang tidak tepat. Fakta menunjukkan selama ini banyak para ibu belum tepat waktu (sebelum 6 bulan) atau terlambat (sesudah 6 bulan) untuk memberikan makanan pendamping ASI (MP-ASI) pada anak. Selain itu para ibu kurang menyadari bahwa sejak bayi berusia 6 bulan sudah memerlukan MP-ASI dalam jumlah dan mutu yang baik. Di sisi lain ada para ibu yang sudah tepat waktu 
dalam pemberian MP-ASI, namun cara pemberiannya yang salah. Misalnya pemberian takaran makan tidak sesuai degan anjuran umur ataupun jadwal makan yang tidak sesuai dengan jadwal seharusnya (Sari \& Warsiti 2017).

Tumbuh kembang anak akan terganggu jika makanan pendamping tidak diperkenalkan pada di usia 6 bulan, atau pemberiannya dengan cara yang tidak tepat. Karena di usia 6 bulan, kebutuhan bayi untuk energi dan nutrisi mulai melebihi apa yang disediakan oleh ASI, dan makanan pendamping diperlukan untuk memenuhi kebutuhan tersebut. Pada usia ini perkembangan bayi sudah cukup siap untuk menerima makanan lain (WHO 2016). Peraturan Pemerintah No 33 Tahun 2012, memberikan makanan pendamping ASI (MP-ASI) yang tepat sejak umur 6 bulan dan meneruskan pemberian ASI sampai umur 2 tahun. Penerapan pola pemberian makan ini akan mempengaruhi derajat kesehatan selanjutnya dan meningkatkan status gizi bayi.

\section{METODE STUDI KASUS}

Studi kasus ini menggunakan metode deskriftif observasional dengan pendekatan continuity of care diberikan pada ibu yang memiliki bayi usia $7-8$ bulan Ny.R di PMB Ernita, Amd.Keb, J1 lobak No.115, Delima, kec. Tampan, Kota Pekanbaru dari 27 agustus - 02 september 2020. Subjeknya Ny. R umur 27 tahun P1A0. Jenis data primer. Cara pengumpulan data anamnesis, observasi, pemeriksaan dan dokumentasi. Analisa data dengan menbandingkan antara data yang deperoleh dengan teori yang ada.

\section{HASIL STUDI KASUS}

Kunjungan pertama kali di lakukan pada tanggal 27 agustus 2020 .

1. Data Subjektif

- Ibu mengatakan masih bingung dengan cara pembuatan MP-ASI yang tepat untuk bayinya.

- Riwayat pemberian nutrisi ASI Eksklusif ya. Lama pemberian ASI 7 bulan, MPASI sejak umur 6 bulan, jenis nasi lembek, Keluhan susah BAB.

\section{Data Objektif}

Tingkat kesadaran :composmentis, Nadi : $114 x /$ menit, Suhu : $36,4^{\circ} \mathrm{C}, \mathrm{P}$ : 36x/menit, TB :66 cm, BB 8 kg.

3. Analisa

Bayi umur 7 bulan dengan pemberian MP-ASI.

4. Penatalaksanaan

1) Menjalin hubungan baik dengan ibu dan keluarga dengan ramah dan sopan. (ibu menerima dengan baik)

2) Menginformasikan hasil pemeriksaan pada ibu dan keluarga bahwa semua normal,bayi sehat, tidak apa-apa.( 
ibu mengerti dengan penjelasan yang telah diberikan, ibu senang dengan kondisi bayinya)

3) menjelaskan tentang MP-ASI meliputi:
a. Pengertian MP-ASI
b. Usia pemberian MP-ASI
c. Hal yang harus diperhatikan dalam pembuatan MP-ASI
d. Jenis dan frekuensi pemberian MP-ASI
e. Pola pemberian MP-ASI ( ibu memahami penjelasan dan akan menerapkannya).

4) Memberitahu ibu, peneliti akan melakukan kunjungan ulang tanggal 29 agustus 2020.( ibu menetahui jadwal kunjungan ulang )

\section{PEMBAHASAN}

1. Data Subjektif

Dalam pelaksanaan asuhan pada by.A ( kunjungan I ) Ibu mengatakan masih bingung dengan cara pembuatan MP-ASI yang tepat untuk bayinya. Dan ibu mengelukan bayinya pada usia 6 bulan saat pertama kali pemberian MP-ASI bayi nya mengalamani susah buang air besar (BAB). Menurut pernyataan ibu bayi pertama kali di berikan makanan nasi yang di hancurkan menggunakan saringan yaitu tekstur yang diberikan langsung kental seharusnya ibu memberi makanan cair. Hal ini tidak sesuai dengan teori, karena pengenalan dan pemberian MP-ASI harus dilakukan secara bertahap baik bentuk maupun jumlahnya, sesuai dengan usia bayi. Pada usia 7 bulan tekstur makanan untuk bayi sebaiknya makanan cair dan lembut seperti bubur buah, bubur susu, atau bubur sayuran yang dihaluskan, agar sistem pencernaan bayi tidak terganggu yang mengakibatkan susah BAB.

2. Data Objektif

Data objektif yang di temukan dari kunjungan I - III yaitu Tingkat kesadaran : composmentis, Nadi : 114x/menit, Suhu : $36,4{ }^{\circ} \mathrm{C}, \mathrm{P}: 36 \mathrm{x} / \mathrm{menit}$, TB :66 cm, BB 8 kg. Data Objektif ditulis berdasarkan fakta real dari pemeriksaan yang dilakukan, baik pemeriksaan utama maupun pemeriksaan penunjan. Dari pemeriksaan yang telah dilakukan tidak ada kesenjangan dengan teori, hasil pemeriksaan dalam batas normal yaitu BB usia 7 bulan 8 - 8,5 dan $\mathrm{TB}=64,8-73,6$ $\mathrm{cm}$.

3. Analisa 
Dari data Subjektif dan

Objektif diatas ditegakan diagnosis berdasarkan

dokumentasi asuhan kebidanan yaitu Bayi umur 7 bulan dengan pemberian MP-ASI.

4. Penatalaksanaan

Penatalaksanaan yang dilakukan pada studi kasus ini sesuai dengan teori yang ada disesuaikan dengan kebutuhan pasien.

\section{KESIMPULAN}

Setelah dilakukan pengkajian sampai evaluasi kasus terdapat kesenjangan antara teori dan praktik di lapangan yaitu ibu memberi MP-ASI dengan tekstur kental pada saat pertamakali pemberian MP-ASI di usia 6 bulan, seharusnya MP-ASI yang diberikan itu dengan tekstur cair.

\section{SARAN}

1. Bagi institusi / pendidikan

Diharapkan institusi dapat meningkatkan kualitas pendidikan bagi mahasiswa dengan cara memperbanyak bahan ajar dan menyediakan lahan praktek sendiri.

2. Bagi lahan praktek

Diharapkan kepada penyedia layanan asuhan kebidanan yang membuka praktik dapat memberikan penyuluhan dan praktek mengolah menu pada ibu yang mempunyai bayi usia 624 bulan tentang pemberian MPASI yang tepat dan sehat sesuai dengan usia bayinya. Agar dapat meningkatkan pengetahuan ibu dan bisa mengolah menunya sendiri sesuai dengan usia bayinya.

\section{DAFTAR PUSTAKA}

Mutalib. 2014. "Pengaruh Pelatihan Pemberian MP ASI Kepada Ibu

Dengan Anak Baduta Di Kecamatan

Sukmajaya Kota Depok Terhadap

Pengetahuan Dan Perilaku

Pemberian MP ASI.” Jurnal

Kedokteran Dan Kesehatan

13(1):80.

Sari \& Warsiti. 2017. "Hubungan Antara

Usia Pemberian Makanan

Pendamping Asi (MP-ASI) Pertama

Kali Dengan Status Gizi Anak Usia

6 - 12 Bulan Diwilayah Kerja

Puskesmas Kombos Kota Manado."

Fakultas Kesehatan Masyarakat

Universitas Sam Ratulangi 1(1):1-7. Sitompul, E. .. 2014. Buku Pintar MPASI : Bayi 6 Bulan Sampai Dengan

1 Tahun. jakarta: langit jakarta. WHO. 2016. Global Report On Diabetes. France: World Health Organization. 
